\title{
176. The Control of Growth and Development in Bombyx mori. IV
}

\author{
Relationship between Environments and Molting \\ or Voltine Characteristics
}

\author{
By Seijiro MoroHoshi \\ Faculty of Agriculture, Tokyo University of Agriculture \\ and Technology, Fuchu-shi, Tokyo \\ (Comm. by Yoshimaro TanaKa, M. J. A., Nov. 12, 1969)
}

In the course of the author's investigations of molting and voltine characteristics. It was found that the effects of environmental factors on molting and voltine characteristics differ quite distinctly at the boundary of early and late instars of larval development. For instance, to obtain diapause eggs, a high temperature is more effective at the early stages, while a low temperature is more favourable at the late ones, and light is more effective at the young stages, but darkness is more effective at the older. In regard to nutrition, to obtain diapause eggs, undernourishment is more effective at the early instars, and good nourishment at the advanced ones. These phenomena seem to be observable not only in the silkworm, but also in other insects. Umeya (1939) pointed out that two physiological periods of the larva are present in many insects besides the silkworm. This fact was made clearer by the atuhor's discovery of the "dominating phenomenon".

There are some genetic characteristics influenced by environmental factors in silkworms. For instance, when normal tetramolting and bivoltine silkworms are kept at low temperature $\left(17^{\circ} \mathrm{C}\right)$ during incubation, some of them tend to become trimolters and most of them lay non-diapause eggs. If a constant relationship between environmental factors and these characteristics could be established, we could get the desired characteristics in silkworms. It was found that a constant relationship between environmental conditions and metabolic characteristics exists. The author has called this the "dominating phenomenon" (Morohoshi, 1957).

Critical point at the middle larval stage. The effects of temperature on larval development differ in the young and following instars. When the larva of a bivoltine race, Shinpaku, is maintained in high temperature $\left(28^{\circ} \mathrm{C}\right)$ or low $\left(24^{\circ} \mathrm{C}\right)$ during total larval stages, the total larval durations in hours are 424 and 508 respectively. Nevertheless, it is interesting that there is very little difference in the cocoon weight of both groups; the former being $1.51 \mathrm{gm}$ and the 
latter $1.55 \mathrm{gm}$. In a group with high temperature $\left(28^{\circ} \mathrm{C}\right)$ in the early instars and low $\left(24^{\circ} \mathrm{C}\right)$ in the advanced ones, cocoons were the heaviest $(1.65 \mathrm{gm})$; while in one with low temperature $\left(24^{\circ} \mathrm{C}\right)$ at the early and high $\left(28^{\circ} \mathrm{C}\right)$ at the late instars, cocoons were the lightest $(1.48 \mathrm{gm})$. In order to obtain a heavy cocoon, high temperature is more effective in the young instars, while a low one is necessary in the advanced instars. Accordingly, a constant temperature, low or high, throughout the larval life shows very little influence on the cocoon weight. Light also shows little effect on the cocoon weight, since weights are similar from insects grown under constant light or in constant darkness throughout the larval life. This is a consequence of the counteracting effects in the early and late instars.

Dominating phenomenon. In silkworms, molting and voltine characteristics are the main physiological ones concerned with selfregulation. There are tri-, tetra-, and penta-molting strains, and there are uni-, bi-, and multivoltine strains. Generally speaking, univoltine females lay diapause eggs irrespective of temperature, bivoltine females incubated at high temperature $\left(24^{\circ} \mathrm{C}\right)$ lay diapause eggs but when incubated at low temperature $\left(17^{\circ} \mathrm{C}\right)$ lay non-diapause eggs, and multivoltine females lay non-diapause eggs irrespective of temperature. The genetic dominance relations are: tri->tetra- $>$ pentamolting and uni->bi->multivoltine.

It is well known that the expression of such characteristics as the number of molts undergoes striking changes under the influence of environmental factors. For instance, the normal larvae are tetramolting. If such larvae are fed well, however, some of them tend to become trimolters. Having found that trimolting is dominant over tetramolting, the author proposed the term "domination" for such a change. If normal larvae are underfed or fed with mulberry leaves to which volcanic ash has been added, some of them become pentamolters. Since pentamolting is recessive to tetramolting, the author called this change "recessivation". Both types of change are phenotypic.

Domination and recessivation together are called the "dominating phenomenon". Another example may also be found in a tetramolting bivoltine race. When eggs of this race are incubated at a low temperature $\left(17^{\circ} \mathrm{C}\right)$, some trimolting larvae (domination) are often obtained, and all the eggs easily change to non-diapause (recessivation). On the contrary, the larvae will remain tetramolting (recessivation) and enter diapause (domination) at a high incubating temperature $\left(24^{\circ} \mathrm{C}\right)$, as seen in Table I.

From another view-point Table I can be represented as Table II. What causes domination in the early stages and recessivation in 
Table I. Effect of temperature on the development of the silkworm during life cycle

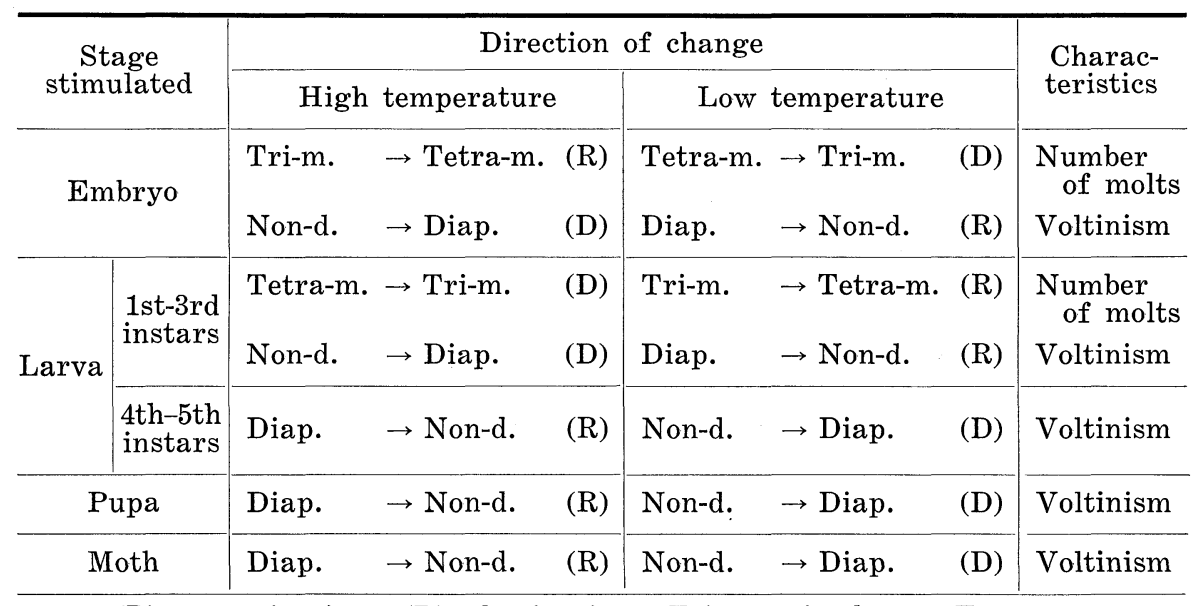

(R): recessivation, (D): domination, Tri-m: trimolters, Tetra-m.: tetramolters, Non-d.: non-diapause moths, Diap.: diapause moths.

Table II. Temperature in relation to domination and recessivation

\begin{tabular}{|c|c|c|c|c|}
\hline \multirow{2}{*}{$\begin{array}{l}\text { Embryo } \\
\text { (incubating } \\
\text { temperature) }\end{array}$} & \multicolumn{2}{|c|}{ Larva } & \multirow{2}{*}{ Pupa } & \multirow{2}{*}{ Moth } \\
\hline & 1st-3rd instars & 4th-5th instars & & \\
\hline $\begin{array}{l}\text { Low }\left(17^{\circ} \mathrm{C}\right) \\
\text { High }\left(24^{\circ} \mathrm{C}\right)\end{array}$ & \multicolumn{4}{|c|}{$\begin{array}{l}\text { Domination } \longrightarrow \text { Recessivation } \\
\text { Recessivation } \longrightarrow \text { Domination }\end{array}$} \\
\hline \multirow{2}{*}{ Medial $\left(21^{\circ} \mathrm{C}\right)$} & $\begin{array}{c}\text { Low }\left(17^{\circ} \mathrm{C}\right) \\
\text { Recessivation }\end{array}$ & \multirow{2}{*}{\multicolumn{3}{|c|}{$\begin{array}{l}\longrightarrow \text { Recessivation } \\
\longrightarrow \text { Domination }\end{array}$}} \\
\hline & $\begin{array}{l}\text { High }\left(25^{\circ} \mathrm{C}\right) \\
\text { Domination }\end{array}$ & & & \\
\hline \multicolumn{2}{|c|}{ Medial $\left(21^{\circ} \mathrm{C}\right)$} & $\begin{array}{l}\text { Low }\left(17^{\circ} \mathrm{C}\right) \\
\text { High }\left(25^{\circ} \mathrm{C}\right)\end{array}$ & \multicolumn{2}{|c|}{$\begin{array}{l}\rightarrow \text { Domination } \\
\rightarrow \text { Recessivation }\end{array}$} \\
\hline & \multicolumn{2}{|c|}{ Medial $\left(21^{\circ} \mathrm{C}\right)$} & $\begin{array}{l}\text { Low }\left(17^{\circ} \mathrm{C}\right) \\
\text { High }\left(25^{\circ} \mathrm{C}\right)\end{array}$ & $\begin{array}{l}\rightarrow \text { Domination } \\
\rightarrow \text { Recessivation }\end{array}$ \\
\hline
\end{tabular}

the advanced ones under low temperature during incubation? The length of each instar and body weight of each instar larvae hatching from eggs incubated at the different temperatures were examined to see why such differences occur. Fig. 1 shows that larval body weight varies with age for both groups but in different ways. Eggs incubated at a low temperature produce larvae which are heavier than those from the high temperature incubation. However, by the 3rd ecdysis the situation is reversed: this reversal stage varying somewhat with the race and environment. When newly hatched larvae are heavy, their growth is accelerated; this elevated metabolism might induce 


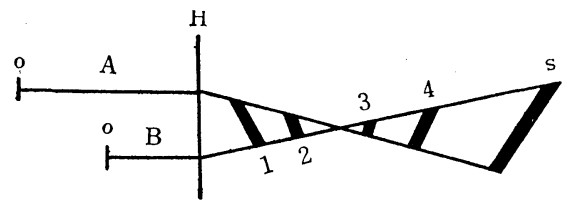

Fig. 1. A diagram illustrating the effect of two different incubating temperatures on the development of the larva. A : low incubating temperature $\left(17^{\circ} \mathrm{C}\right), \quad \mathrm{B}$ : high incubating temperature $\left(24^{\circ} \mathrm{C}\right), \mathrm{H}$ : hatching, $1,2,3,4$ : respective molting, S: spinning. Length of line is a function of time and height of line is a function of weight. Why does A line go down? This implies that larva gets lighter as it grows.

the appearance of dominant characteristics (trimolters) during early larval development and recessive characteristics (non-diapause eggs) during advanced stages of development.

If bivoltine silkworm eggs are incubated at medium temperature $\left(21^{\circ} \mathrm{C}\right)$, and the hatched larvae are reared at low $\left(17^{\circ} \mathrm{C}\right)$ or high $\left(25^{\circ} \mathrm{C}\right)$ temperature during the early larval instars, tetramolters of the low temperature group tend to produce batches of diapause eggs. If "bivoltine silkworms" are reared at a low temperature during the late larval stage after the late embryonic and early larval stages are treated at the medium temperature $\left(21^{\circ} \mathrm{C}\right)$, their metabolism is depressed, and the female moths produced lay diapause eggs. Low temperature conditions during pupal stage induce depressed metabolism and such female moths produced lay diapause eggs. That is, the number of generations is decreased when metabolism during late larval and pupal periods is depressed, whereas the opposite is true if metabolism is raised.

Discussion. The facts that in the younger and older larval instars the larvae show quite distinct reactions to temperature, light and nutrition seem to be due to an antagonistic physiological balance. We already know that the corpus allatum secretes a metabolismaccelerating hormone, and its titre gradually diminishes with age. The suboesophageal ganglion secretes a metabolism-decelerating hormone, and its titre gradually increases with age. These two hormones act antagonistically on each other, and the relative effects of these two hormones are as shown in Fig. 2. Thus a critical point throughout the larval life exists in the 3rd instar. Accordingly, although molting and voltine characteristics are strictly determined by the antagonistic action of the two hormone, molting characteristics are predominantly determined by the function of the corpus allatum during early stage of the development, and voltine characteristics are predominantly determined by the function of the suboesophageal 


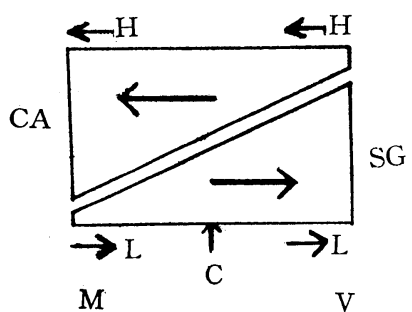

Fig. 2. A diagram illustrating the influence of different temperatures on molting and voltine characteristics in the early and late developmental stages.

CA, SG: respective functions of the two kinds of hormones, H, L: high and low temperatures, $\leftarrow$ : raised metabolism, $\rightarrow$ : depressed metabolism, C: critical point at the 3rd instar, M: early development, V: late development. The molting characteristic is determined by relative functions of the two hormones during early development and voltinism is determined by relative functions of the two hormones during late development.

\footnotetext{
Molting characteristic $\quad\left(\mathrm{H}, \mathrm{CA} / \mathrm{SG}\right.$, larger, domination $\left(M^{3} \leftarrow+M \leftarrow M^{5}\right)$

during early development $\left\{\mathrm{L}, \mathrm{CA} / \mathrm{SG}\right.$, smaller, recessivation $\left(M^{3} \rightarrow+M \rightarrow M^{5}\right)$

Voltinism during late $\quad\left\{\mathrm{H}, \mathrm{SG} / \mathrm{CA}\right.$, smaller, recessivation $\left(V^{3} \leftarrow+V \leftarrow V^{1}\right)$

development

$\left\{\mathrm{L}, \mathrm{SG} / \mathrm{CA}\right.$, larger, domination $\left(V^{3} \rightarrow+V \rightarrow V^{1}\right)$
}

ganglion during late stage of the development, as shown in Fig. 2.

What causes domination during early larval development and recessivation during advanced stages of development under low temperature during incubation? Newly hatched larvae which have undergone embryonic development at a low incubating temperature are heavier than those incubated at a high one, while matured larvae from a low incubating temperature are lighter than those from a high one. When the newly hatched larvae are heavy, their growth is accelerated; this elevated metabolism might induce domination of molting characteristics during early larval development. Pupal metabolism may be raised in lighter body weights than in heavier ones under the same temperature. This lighter body during advanced stages of development seems to make voltinism recessive. That is, when incubated at a low temperature, the molting characteristic is made dominant and voltinism is recessive (domination $\rightarrow$ recessivation type). These relationships are as shown in Table II. When eggs are incubated at medium temperature, and the larvae hatched are reared at low or high temperatures during early larval development, the silkworms from the low temperature group show another developmental type, recessivation $\rightarrow$ recessivation type, as seen in Table II. Although these larvae are heavier than those from the high temperature group at the 3rd instar, their body weight is lighter by the time they 
reach maturity (Morohoshi, 1957). Accordingly, the molting characteristic under the influence of a low temperature during early larval development is made recessive by depressed metabolism, and voltinism is also recessive by raised metabolism owing to lighter body weight.

Variations of molting and voltine characteristics with temperatures during early and late larval development are as shown in Fig. 2. The developmental mode of the silkworm larvae varies throughout the larval period. That is, when heavy during early larval development, the larvae become lighter during late stages. When larval duration is shortened by elevated metabolism during early larval development, it is delayed during late larval development. There exists a time-law of the development. When domination by raised metabolism arises during young larval development, recessivation occurs during older larval one.

Acknowledgement. The author wishes to express his gratitude to Professor Robert C. King, Northwestern University, Illinois, for reading the manuscript.

\section{References}

Matsumura, S., and Ishizaka, Y. (1929): The effect of temperature on the development of Bombyx mori. Rep. Nagano Seri. Exp. Sta., 9, 1-136.

Morohoshi, S. (1957): Physiogenetical Studies on Moltinism and Voltinism in Bombyx mori. A New Hormonal Antagonistic Balance Theory on the Growth. Japan Soc. Prom. Sci. Tokyo, 1-202 (book).

Umeya, Y. (1939): A consideration on the wintering of insects from a stand-point of the life cycle of the silkworm. Zool. Mag., 51, 451-462. 